\title{
The War between $n+l$ and the Elegant Variation, or When Production Overlooks Consumption in the Literary Political Economy
}

\author{
Elisabeth Chaves
}

\section{The War between $\mathbf{n}+1$ and the Elegant Variation}

\begin{abstract}
"At a time when older forms of media are supposedly being swallowed up by newer ones, the impulse to start the kind of magazine Partisan Review was in the late 1930's or The Paris Review was in the 50's might look contrarian, even reactionary. If you are an overeducated (or at least a semi-overeducated) youngish person with a sleep disorder and a surfeit of opinions, the thing to do, after all, is to start a blog. There are no printing costs, no mailing lists, and the medium offers instant membership in a welcoming herd of independent minds who will put you in their links columns if you put them in yours. Blogs embody and perpetuate a discourse based on speed, topicality, cleverness and contention - all qualities very much ascendant in American media culture these days. To start a little magazine, then - to commit yourself to making an immutable, finite set of perfect-bound pages that will appear, typos and all, every month or two, or six, or whenever, even if you are also, and of necessity, maintaining an affiliated Web site, to say nothing of holding down a day job or sweating over a dissertation - is, at least in part, to lodge a protest against the tyranny of timeliness. It is to opt for slowness, for rumination, for patience and for length. It is to defend the possibility of seriousness against the glibness and superficiality of the age and also, of course, against other magazines" - The New York Times (Scott 2005).
\end{abstract}

Many assert that the Internet has been and will continue to be a transformative space or medium. It overcomes the limitations of real space, diversely capitalism, restrictions of access, or authority (depending on whom you talk to), and creates a channel in which more voices can be heard. The nature or degree of this transformation will be discussed further below. Taking advantage of that alleged space for change are numerous literary weblogs or "litblogs." These relatively new places for literary critique and expression have multiplied like mad in recent years, resulting in the establishment of The Litblog Co-op, a litblog dedicated to "uniting the [self-described] leading literary weblogs [twenty-one to be exact] for the purpose of drawing attention to the [self-defined] best of contemporary fiction, authors and presses that are struggling to be noticed [presumably as defined by sales] in a flooded marketplace" ("The Litblog Co-op" 2007). This antiestablishment attitude and concentration on the independent, nonmainstream and overlooked is widely shared among the blogs, which number many more than the twenty-one self-positioned members of the co-op. By their own and others' descriptions, the combination of this rebellious spirit and scope of interest are what supposedly create the potential for transformation of the current book culture, or at a minimum, provide a space for the underdogs to reach wider audiences (Dotinga 2005; Keener 2005; "The Litblog Co-op" 2007; McLemee 2005; Press 2005; Tucker 2006; Rich 2007).[1] Further, the litbloggers themselves stand outside the establishment, or at least, separate enough to critique but sometimes to benefit from its workings, many lacking any direct ties with establishment institutions, although several in recent times have published reviews with print outlets.

As a result, the establishment (or the established print media that reviews books) have on occasion taken shots at these unwelcome upstarts. The establishment has built up its reputation as the repository of expertise, and it fears 
the erosion of this status by the democratization (read dumbing down) of opinion that the litblogs threaten. They have historically determined what is good, what is bad, and what is mediocre. Moreover, they authenticate through their process of "expert" vetting creating what is accepted as true, and greater still, they produce the codes and conventions that constrain discourse through their editing. With the advent of on-line book culture, print media may lose its role as gatekeeper of what people are exposed to and presumably read. Surprisingly then, perhaps, the latest war[2] between the litblogs and the print media has occurred between a more established litblog, The Elegant Variation, [3] and the newcomer, anti-establishment print journal, $\mathrm{n}+1$.

To label what is largely a heated exchange of words a war is probably an overstatement. It is more like a skirmish or even a scuffle. What determines the magnitude of a war anyway - its content or its effect(s)? However, the exchange has generated some heat (and incessant back and forth commentary from those involved and numerous others on several blogs).[4] Importantly, the fight questions the binary of Internet as democratic, antiestablishment space and print media as anti-democratic, establishment space. As the opening quotation claims, perhaps the real battle is over speed. The Internet allows fast publication of thought, which some argue is inherently faulty, while print media is slow and hence more thoughtful, which others criticize for its incongruity with our "fast capitalism" times. However, as this paper will argue, speed may not be the end of the story.

\section{A Short Description of the Antagonists}

Mark Sarvas, a self-described "contented defiler of prose" and published writer, is the author of The Elegant Variation, a litblog in existence since about 2003. (The nature of the Internet makes dating websites a difficulty). The litblog's title is a reference to author Henry Watson Fowler's term for the unnecessary use of synonyms to mean a single thing, or as Sarvas describes on his site, "the inept writer's overstrained efforts at freshness or vividness of expression" (2007a). The litblog provides the author's own reviews of featured books, guest reviews of books, general literary news taken from other media sources, and links to current literary events.

$\mathrm{n}+1$ began in 2004 and is a political, cultural and literary print journal published twice a year. Keith Gessen, Benjamin Kunkel, Mark Greif and Marco Roth founded the journal in New York City and continue to edit it with the help of managing editor, Allison Lorentzen. They are also frequent contributors. Additionally, the journal maintains a website, located at www.nplusonemag.com, and is webmastered by Chad Harbach, also a member of the editorial board. The website offers some content not available in the journal, but none of the print edition's content is available on-line. The journal's name is described by Editor Mark Greif as a mathematical title that "invokes 'a series that doesn't come to an end' at a time when people speak of perfected democracy and the end of history" (Shapiro 2004). The journal's editors self-compare it, hopefully in modest aspiration, to the now defunct Partisan Review, a political and literary quarterly that ran from 1934 until 2003. n+1 was a 2006 winner of an UTNE Reader Independent Press Award in the Writing category.

\section{The Scuffle}

In the Winter 2007 issue, the fifth issue to reach the presses since the journal's inception in 2004, $\mathrm{n}+1$ featured an article titled "The Blog Reflex: Blog Me with a Spoon." The article appeared in the opening pages of the journal, titled "The Intellectual Situation," an unauthored section presumably co-written by the journal's four founding editors. The short piece took direct aim at the litblogs.

"The Blog Reflex" began by decrying the nature of blogs in general - the "blogs" of corporate media, the negative effects of onslaughts of meaningless information, the failure of political blogs not to write but to link, and the commodification of blogs. The critique then focused its attention on the litblogs, likening them by a bit of an extension to Virilio's theory of the accident. Virilio's theory of the accidents produced by each new stage of technology is "what happens unexpectedly to the substance, the product or the recently invented technological object" and is "the hidden face of technological progress" (Redhead 2006). It may be interpreted as what should be predicted and prevented but what at the same time becomes impossible to predict and/or prevent in our sped up and globalized world. Here, the accident for $n+1$ appears to be the destruction of critical thinking on-line, the contingent result of the seemingly positive emergence of the blog, a new forum for anyone's expression. [5] 
The $n+1$ piece had two main beefs with the litbloggers. First, the litbloggers were a big let-down. Rather than "democratize the intellectual sphere," they turned out to be "unwitting stenographers of hip talk and market speak" (“The Blog Reflex: Blog with Me a Spoon” 2007:6).

The need for speed encourages, as a willed style, the intemperate, the unconsidered, the undigested. (Not for nothing is the word blog evocative of vomit.) "So hot right now," the bloggers say. Or: "Jumped the shark." The language is supposed to mimic the way people speak on the street or the college quad, the phatic emotive growl and purr of exhibitionist consumer satisfaction - "The Divine Comedy is SOOO GOOOD!"-or displeasure-“I shit on Dante!" So man hands on information to man (“The Blog Reflex: Blog with Me a Spoon” 2007:6).

The second critique rebuked the litbloggers for being wolves in sheep's clothing, labeling them "a perfection of the outsourcing ethos of contemporary capitalism," as they morphed into marketing machines with an "aura of indie cred" ("The Blog Reflex: Blog with Me a Spoon" 2007:6). Why should corporate publishers pay for marketing when litbloggers serve their interests for free? (Or mostly free - some bloggers do make money from advertisers, and most get free, advance copies of books.) $n+1$ finished off the litbloggers by in effect likening their community to a self-congratulatory group of publicity hounds that seek not just to advertise books but also to market themselves.

So much typing, so little communication... It's incredible. A bottomless labor market exists in which the free activity of the mind gets bartered away for something even less nourishing than a bowl of porridge. And you can't dine off your inflated self-respect and popularity—not unless you get enough hits to sell advertising ("The Blog Reflex: Blog with Me a Spoon" 2007:7).

The blogs were quick to respond to the attack. A contributor to Long Sunday, a political theory blog, provided one of the earliest responses in mid-February, around the time that issue five came out. In essence, the poster, who goes by "CR," wanted to know if Long Sunday belonged to the category of litblogs that n+1 criticized. After following a post on another blog “and having clicked through to his links to actual 'litblogs,' I now can totally see n+1's point... I guess I was thinking that we are a litblog. Fortunately, that doesn't seem to be the case....” (CR 2007).

In early March, the litblog, The Millions, posted a long critique of the $n+1$ piece. The poster, Garth Risk Hallberg, both agreed and disagreed with $n+1$ 's characterization of litblogs. He asked, though, that $n+1$ refrain from becoming the subject of its own critique, namely making hasty judgments and foregoing reflective examination.

Communication requires both speakers and listeners, and by making common cause with like-minded bloggers, $\mathrm{n}+1$ might swell the ranks of the enlightened, rather than going the genteel way of the salon. To that end, its introductory essaylets would do well in the future to forgo simplistic binary code - Literary Blogs: Thumbs Up Or Thumbs Down? - in favor of sustained, thoughtful analysis (Hallberg 2007a).

Mark Sarvas at The Elegant Variation then linked to Hallberg's critique on his own blog:

The Millions justly takes $n+1$ to task for its unsigned jeremiad "The Blog Reflex," about which more anon. What neither piece notes is how assiduously $\mathrm{n}+1$ courted bloggers at its inception, and how thin-skinned its editors have been concering [sic] any criticism of their efforts. Also more of which, anon (Sarvas 2007f).

In subsequent posts, Sarvas reproduced e-mails from n+1 editor Keith Gessen in which Gessen responded to Sarvas's request for a copy of the journal's first issue with a description of the journal's mission and then in a later e-mail wondered if Sarvas had received the copy of the issue they sent and would be commenting on it in his blog. Sarvas hoped that these e-mails from Gessen would highlight $n+1$ 's hypocrisy in first courting litblogs and then later laying waste to them (Sarvas 2007c; Sarvas 2007d; Sarvas 2007e).

The posts on all three blogs, Long Sunday, The Millions, and The Elegant Variation, incited strong reactions from the on-line community, many from other bloggers with seemingly widely-read blogs. Many comments were submitted to each of the posts, especially to The Elegant Variation. Some of the comments took sides. Others gave critiques of the battle itself, ranging from criticisms of Sarvas's posting of supposedly private e-mails from Gessen to the battle's overall appearance of pettiness. $n+1$ editors, Keith Gessen and Marco Roth, both posted several comments (or rebuttals) in response to the posts on each of these blogs. In response to Sarvas's intimations that more e-mails from $n+1$ would be reproduced on his site, Gessen preemptively copied two more e-mails he had sent to Sarvas, self-described as a mean e-mail and an apologetic follow-up, into a comment on the initial post.

Sarvas's next and promised to be final response came in the form of a lengthy account of why he reacted as he did (which included some apology), why he disagrees with $n+1$, and why he is critical of $n+1$ as a journal (Sarvas 
2007b).[6] He, like Hallberg, commented on the irony of $n+1$ 's critique of blogs that consisted of many of the same shortcomings they find in blogs_-generalizations, lack of thoughtfulness, and hastiness to judge. Additionally, he characterized the journal as having "anger" as a mission statement. Sarvas provided an advanced copy of the post to the $\mathrm{n}+1$ editors giving them the opportunity to comment before he added it to his site. Their response, prepared by Keith Gessen, was brief. He provided links to various print media pieces in mass audience publications that each of the editors had written, ostensibly to contradict Sarvas's criticisms of the quality of their writing. The written portion of the response was only "Yup, we're angry. There's a lot to be angry about. Now piss off."

\section{The War Amplified: The Disappearing Print Review Struggles to Remain Vital}

The dispute between $n+1$ and The Elegant Variation is positioned against a backdrop of a larger struggle to keep book culture's presence in major daily newspapers. While publications like The New York Review of Books remain alive and vital, their readership is only 280,000, a fraction of the Los Angeles Times' readership of 6.4 million (Wasserman 2007). However, the Times recently cut back on its book review section, joining it with another section, and promoting a larger on-line presence for book reviews. Only five national papers now maintain stand-alone book review sections and those too have diminished in size over the past twenty years (Trachtenberg 2007). After the Atlanta Journal-Constitution eliminated its book editor in 2007, the National Book Critics Circle (NBCC) began a "Campaign to Save Book Reviewing" that included a "Read-In!" at the AJC's headquarters and an on-going series on their blog, Critical Mass, featuring "concerned writers, op-eds, Q and As, and tips about how you can get involved to make sure those same owners and editors know that book sections and book culture matter" (Freeman 2007).[7] The NBCC's use of electronic media, and specifically, the blog form, to protest against the disappearance of book reviews in print demonstrates the complex relationship between electronic and print media.

Some finger pointing for the decline of book reviews in newspapers has been directed at the blogosphere, and the tension between print media and on-line reviewing also erupted into a nasty exchange in the United Kingdom (Cooke 2006). There, a literary critic for a national newspaper bemoaned the poor influence of the Internet on book reviewing. In response, a novelist and blogger fired back a sharp reply on her blog. Her thoughts were echoed by some others on-line, while a literary editor informed her that none of her future print publications would be reviewed, either positively or negatively, in pages of this editor's publication.

Steve Wasserman, a former editor of the Los Angeles Times Book Review, argues that newspaper book reviewing has never made money for newspapers and also has never reached a high level of quality, citing indictments against poor book reviewing made by James Truslow Adams in The Saturday Review of Literature in 1931, Elizabeth Hardwick in Harper's Magazine in 1959-Hardwick went on to help found The New York Review of Books in 1963 - and Jay Parini in The Chronicle of Higher Education in 1999 (2007). The disappearance and shrinking of these sections from newspapers in the last few years may then be just a part of the struggle for survival for print national newspapers in general as competition from television and on-line news decreases their circulations. Newspapers axe the sections to produce the least advertising revenue first. Book reviews in print media may in future only reach the comparatively limited audiences that subscribe to the New York Review of Books, The London Review of Books, The New Yorker, and like print publications.

The war between $n+1$ and The Elegant Variation and the decline of print reviews in national newspapers suggest a more complex problem for interested observers than simply the question what is the Internet's effect on literary criticism. In review, $n+1$ 's main criticisms of the litblogs included the following: first, their utilization of the Internet failed to democratize the intellectual sphere; second, they became promotion machines rather than critical beings; and third, they opened up new areas to commodification as they marketed themselves. $\mathrm{n}+1$ laid the blame on the litbloggers as users of the Internet, criticizing the message rather than the medium, and perhaps overly focusing on the production of blogs as textual vomit rather than considering the audience of both these texts and their own.

The underlying question is whether the Internet acts as a space for transformation of our current literary political economy that has substituted exchange value for use value, regardless of the user or the user's intentions. Is literary culture on-line sufficiently different from the literary political economy that already exists in the off-line world? By focusing on the form of critical thought on-line, the role it may play as a practice of resistance, and its consumption or non-consumption, this paper hopes to provoke further discussion about the supposed democratizing effects of the Internet rather than continue the binary battle of print versus digital. 


\section{Beyond Binaries: What the War is Really About}

\section{Whether Content Can be Divested of Form}

One criticism of the Internet is that it represents only changes in the form but not the substance of knowledge, communication, thought and so forth (May 2002). This judgment while arguably having much merit simultaneously diminishes the importance of form. If it is the case that the Internet only changes the form of discourse and not its content, then how much of a difference does a change in form make-enough of a difference to begin to change the substance? One of the primarily specified changes in form is speed and its effects. In fact, much of the debate between $n+1$ and the litblogs seemed to center on this issue. In simplified terms, the speed of the Internet allows for quick communication, and quick communication is inherently unthoughtful. The title of the $\mathrm{n}+1$ piece, "The Blog Reflex," highlighted this tendency for Internet writing to be some sort of compulsory reflex rather than deliberative act.

Agger labels this tendency for unreflective thought a consequence of instantaneity (2004). However, as some of the comments in reaction to the piece identified, $n+1$, a journal that is only produced twice a year, also portrayed some of the traits associated with unreflective thought. Further, some of the on-line comments themselves displayed a deliberative process of thought albeit produced in a short span of time. Moreover, even though the political theory blog Long Sunday was quick to distance itself from the lesser litblogs, it is also a blog produced on the Internet and updated on usually a daily basis. Its chief commentators are academics with presumably full and busy schedules, fitting in blogging with other forms of writing more valued in higher education (i.e., publications in print media). Still, they find time to produce posts for a blog that tries to be reflective. So, as asked before, is speed really the end of the story?

The war between The Elegant Variation and $n+1$ is a war with two theaters. One of the opponents is located on the Internet while the other's home is the printed page. The question then became where will the war be fought? This war largely took place on the Internet after the initial shot was fired from the printed page. Interestingly, and as several commentators to the battle pointed out, finding a copy of the $n+1$ piece is difficult. As noted earlier, the journal does not reproduce any of the pieces contained in its print editions on its website. Therefore, to read the piece, one has to go out and buy it or subscribe to the journal. Aside from big cities and college towns, most local bookstores may not carry it. Several people, including Sarvas, requested that the journal put "The Blog Reflex" on its website as it seemed only fair to make a piece criticizing on-line media accessible to the subjects of its critique.[8] Again, the war largely took place on the Internet. Two of the $n+1$ editors participated in the blogs by posting several comments of varying length and seriousness. Was this participation self-defeating as they allowed the battle to be played out on "enemy ground?" Is the ability of the Internet to provide a forum for such arguments a positive or negative addition to public discourse?

If such a battle had taken place within the pages of a print journal, in all likelihood, the journal would have lost some, if not all, of its credibility. At the risk of seeming stodgy and conservative, even the more radical journals attempt to cultivate an aura of authority and expertise. In many ways, print media appears inherently more authoritative than blogs. The quotation located at the opening of this paper suggests that the editors of $n+1$ chose the form of print media over the blog because print media better lends itself to seriousness of thought. But there are two ways that this seriousness can perform. First, seriousness as a vehicle of thought allows the author to write more contemplatively, presumably better expressing her/himself. Second, seriousness as a indicator of authority prevails upon the audience to respect the author's words as representing truth. Then, to choose a print journal, still considered (although subject to future change) as inherently more authoritative and even authentic, is to ease the burden of convincing the audience of your position.

On-line bloggers must struggle much more to convince their audiences of their positions, if such a struggle is even important to them. However, since blogging can be taken up by anyone with access to a computer and the Internet and rudimentary computer skills, more people can attempt to contribute serious thought. Literary criticism is no longer confined to a group of elites that have acquired a certain set of institutional markers that brand them as "official critics." Others may have valuable opinions to share. But what is the nature of the added value?

The form of the Internet as currently constructed and utilized creates a huge ocean of writers. The impossibility of reading even one percent of the information contained on the World Wide Web should be apparent to anyone. Still, writers continue to contribute texts to this galaxy of words. Agger argues that the rate of textuality is in an inverse relationship to the rate of discourse (Agger 1990). With everyone talking or writing, no meaningful 
conversation can be held. For those arguing that the Internet's form allows for a more democratic public sphere, then some meaningful discourse must be occurring on-line. However, merely giving anyone and everyone the opportunity to speak/write cannot be held to be a democratic improvement. "The antidote to a silenced public sphere is not a cacophonous one in which everyone talks and no one listens” (Agger 1990:93).

For example, one of $\mathrm{n}+1$ 's criticisms of blogs in general is that they merely "link" to other sites and texts rather than produce any original work. The linking creates a form that is more focused on events rather than topics, a critique similarly made of television news media (Altheide 1987). Rather than create a sustained emphasis on any one topic, the litblogs hop from event to event, whether the release of a book, the announcement of a book award, or a juicy book scandal. The hyperlinks allow them to piece together an array of information sound bites that lack a coherence or cohesiveness other than that they all have to do with books. Keeping up on the news in the book world may hold value for some, but the practice of linking detracts from the creation of a meaningful public discourse, or even a public itself, as discussed more below. Even if a blog does sustain a discussion on a single topic over a period of time, the question then becomes whether the format of the blog easily allows a reader to follow and to contribute to the discussion? The front page of the blog can only hold so many posts, and a reader necessarily has to sift through previous posts and tie together diverse commentary on the chosen topic to see a conversation emerge. If some of the postings contain links, then the reader must also travel across and between sites to follow the conversation's thread.

It is not texts themselves that create publics, but the concatenation of texts through time. Only when a previously existing discourse can be supposed, and a responding discourse be postulated, can a text address a public. Between the discourse that comes before and the discourse that comes after, one must postulate some kind of link. And the link has a social character; it is not mere consecutiveness in time, but a context of interaction" (Warner 2002:62).

These digitally, rather than socially, linked journeys through time and space are journeys without end as the Internet resembles infinite information. The very purpose of the journey is often forgotten, and the reader becomes enthralled to an information spectacle.

The litbloggers' practice of linking also emphasizes the intertextuality of their form. In literary theory, intertextuality "denotes ways in which works of art - especially of literature - are produced in response not to social reality but to previous works of art and the codes and other conventions governing them" (Sebeok 1985: 657). Intertextuality is not confined to art but is also evident "across writing genres and related to more epistemologically explicit issues" such as global politics (Shapiro 1989:11). Rather than creating a new class of literary work or genre, litbloggers engage in a process of intertextuality that responds to previous aesthetic codes but also political codes that are embedded in our literary political economy. In this sense, rather than producing a new, alternative book culture, litbloggers instead may be solidifying the dominant codes and conventions that are already in place. Litbloggers may, and some do, avoid being accomplices to the reification of dominant discourses by not only providing links but also challenging the source of the links. This is where their power of critique lies and perhaps where they may exercise more freedom than print media whose codes and conventions have concretized since the development of print over fifteen hundred years ago.

Still, while print media may be more complacent with a larger assured audience and may not be able to take the risks that an on-line author can, a greater responsibility to seriousness of thought may produce more reflective thought, and with fewer print publications, many carry large audiences. Even the relatively small audience of the New York Review of Books $(280,000)$ is still much, much larger than the audience of The Elegant Variation, which averages 5,000 to 7,000 hits a day (Getlin 2007). But on-line texts with any measurable audience are still largely reproducing thought that is a mirror image of what can be found in print media while simultaneously deteriorating such thought due to the speed of its production and the quantity produced. The result is the creation of more noise than signal. Lone rangers with smaller cliques or readerships of one may be an exception, but their existence begs the following question.

\section{Whether Practices of Resistance Can be Meaningful Without Consideration of Audience}

Both the litblogs and the journal, $n+1$, attempt to practice forms of resistance, but how is resistance defined or identified? Michael J. Shapiro (1991) provides a useful distinction between a critical theory understanding and a Foucauldian understanding of resistance. According to Shapiro, critical theorists view resistance as a counteraction to 
a dominant ideology that can ultimately reveal the falsity of the ideology, while Foucault's genealogy posits resistance as continuing struggles that rework and remake the temporarily fixed structure of intelligibility in an ever evolving discourse (1991).

Following Marx, critical theorists, such as the members of the Frankfurt School, argue that commodity fetishism produces a false consciousness that reads the world as both fixed and rational (Agger 1991). Marx explains commodity fetishism as the substitution of social relations between men by relations between things (n.d.). Things that have entered the marketplace of capitalism have taken on an objective existence of their own. Ties between a commodity's existence and its origins as the labor of an individual are severed. Further, a commodity appears to have a social character only when it is exchanged (Marx n.d.). In attempting to explain why capitalism has yet to fail, the critical theorists turned to culture and ideology that aid capitalism by deepening commodity fetishism (Agger 1991). This deepening through the continued exploitation of worker's surplus value along with the dominance of the culture industry produces a false sense that no real change can occur.

For Horkheimer and Adorno, thought has reified and has become stuck on "repeat." "As a result, the word, which henceforth allowed only to designate something and not to mean it, becomes so fixated on the object that it hardens to a formula" (2002:133). It conforms the world to itself so that nothing appears new. The critical theorists pay close attention to the interventions of the state and culture in securing the seemingly fixed position of capitalism in our society. Their analyses critique dominant institutions and dominant discourses, such as positivism, that have become institutionalized.

Foucault (1997) supplemented the techniques of production, signification or communication, and domination, with the technique of the self. The idea being that individuals govern their own subjectivity through the technologies of the self. This notion opened the door for a greater understanding of power and freedom. What interested Foucault was the notion of techniques of the self as the creation of the self as a piece of art, "the idea of the bios as a material for an aesthetic piece of art," rather than leaving art to the experts (1997:260-261). For Foucault, the subject is not an essence, but the product of subjectification. The self takes on different forms in the different roles it plays.

Foucault emphasized that power was about relations of power, and that relations of power are possible only as long as the subjects involved are free (1997). If the possibility of resistance, in whatever form, is not present in a relationship, then no relation of power exists. As power exists throughout all relationships, institutions, and structures, freedom also exists. In this sense, power is productive. However, domination occurs when power is too one-sided. The problem for Foucault was how to avoid or manage the possibility of domination. "I believe that this is, in fact, the hinge point of ethical concerns and the political struggle for respect of rights, of critical thought against abusive techniques of government and research in ethics that seeks to ground individual freedom" (Foucault 1997:299).

He also believed that his concept of governmentality revealed the possibility of the freedom of the subject and its relationship to others (Foucault 1997). In a sense, the possibility of freedom is simply understanding the world in different terms, rather than participating in violent revolution. Foucault's aim was to reveal how we came to have a certain understanding of the world and impress upon us that our understanding was contingent, that it depended upon exclusions of alternative conceptions of reality. Crampton takes up the Foucauldian notion of resistance as a practice or technique of the self. He defines practices of resistance, like blogging that he terms "self-writing," as "a form of resistance to normalization because they are where one works on oneself in a process of becoming," emphasizing not the content of the blog but the process (Crampton 2003:104). To oversimplify, critical theorists view resistance as a collective struggle, while Foucault's technologies of the self can be practiced successfully by the individual.[9]

$\mathrm{n}+1$ takes seriously its mission to be a dissenting voice, hoping to follow in the footsteps of former journal, The Partisan Review, and in the work of the Frankfurt School. Similarly, the litblogs claim to be fighting against a literary scene dominated by big box bookstores, mega on-line stores like Amazon, and a narrowing of the literary review world, as witnessed by the shrinking number and size of book review insert sections in newspapers. Perhaps the two view resistance differently $-\mathrm{n}+1$ follows the tradition of the Frankfurt School that defines resistance as opposing a dominant ideology that can be revealed as false, while the litbloggers practice the Foucauldian techniques of the self, their writing acting as a process of continual revision. However, as argued above, the litbloggers' practice of intertextuality may solidify or reify what is already in place rather than transform. Perhaps to assign this difference of understanding to the journal and the litbloggers is only to make use of a helpful heuristic that provides space for a functional analysis but at the same time may also homogenize or distort. Still, since the journal and the litbloggers 
seem to have assigned these positions to themselves within their own discourses, it may be helpful to carry this argument forward.

If both sides of the war are practicing resistance, albeit within different constructions but with perhaps a similar goal, then the question becomes whether this is a civil war? Is the same side fighting itself? And if so, what are the reasons and what are the consequences? In a sense, this war is a fight over audience. The acquisition of an audience by an author may be seen as a validation of what is written. As Sarvas in his promised last post on the subject thoughtfully asks, "Doesn't the literary ecosystem allow for both what $\mathrm{n}+1$ offers and what The Elegant Variation offers?" (Sarvas 2007b). Is the audience for anti-establishment practices of resistance and critical thought so small that the players must fight each other for relevancy? $n+1$ seems to be criticizing the litblogs for not taking their practices of resistance seriously enough. In reply, the litblogs challenge whether a journal with a relatively small audience, an elite educated authorship, and a largely inaccessible style can practice resistance any better.

But to follow the argument presented above, that the journal and the litbloggers view resistance differently, the better question seems to be whether both practices of resistance fit a definition of the political that seeks to change the world? This question recurs to the well-established argument between aesthetics and politics and whether one or the other holds some position of preference in its capability of altering the world for the better. Can art that is produced by an individual without an outward, visible affiliation to any collective or collective understanding be a political act? Must Bob Dylan stand for something? - admittedly a somewhat facetious question. The same question should be asked of Foucault's individual who practices technologies of the self ? Crampton argues that blogging as a practice of resistance is necessarily an individual form of resistance, as it involves working on oneself. "The point of the blog is not the content: it is the form, or process itself: self-writing" (Crampton 2003:105). Perhaps the litblogs, even the ones that $n+1$ criticizes as valueless, have value for their authors as practices of resistance. Nevertheless, many of the more prominent litblogs appear to be read. Does a litblog with value for the author necessarily produce value for the audience?

There may be value to the individual, as noted above, in self-expression or self-writing. There may be value to the public in increasing the size and scope of publications that are produced, distributed and read. But do these added values necessarily translate into an improvement of the political? The nature of litblogs in an abstract sense creates a tension within the book culture between the need for self-expression and the expansion of what literature should reach an audience (an improvement of the individual) and the need for public discussion necessarily centered around a more finite set of texts (an improvement of the relationship between the individual and the collective). Through the lens of critical theory, $n+1$ condemns existing litblogs to a subsidiary role within the culture industry as failing to further any critical discussion and simply being marketers of books and themselves, neither improving the individual nor the collective.

Brenkman (1979) uses Sartre's concept of seriality to analyze the effect of mass media on the relationship between the individual and the collective.

\footnotetext{
Mass communication addresses the separated subject as constituted by the exchange and consumption of commodities. It produces a relation between the subject and the collective akin to what Sartre calls seriality - the series being a grouping in which the members are connected with one another only insofar as they are isolated from one another (Brenkman 1979:99100).
}

Arguably, litblogs are not a true form of mass media since their audiences are not what we would commonly think of as "mass" (Rich 2007). Still, like mass media, they also appear to create a serial relationship between the individual and the collective. For example, returning to one of n+1's criticisms that litblogs merely "link," one can see how seriality is both produced and consumed on-line. Sarvas claims that " $t$ ] he Web does certain things uniquely well, coupling immediacy with multimedia and a profound sense of interconnectedness, courtesy of the humble hyperlink" (Sarvas 2007g). However, this "sense of interconnectedness" as promoted by the link is a false sense of attachment.

Blogs, whether read by ten or ten thousand, have audiences that are groups but are separate from each other within those groups. They are serially connected to one another through the reading of the blog. They are not an association with the blog as their mouthpiece. The practice of linking further emphasizes this seriality with the bloggers not being content to create and sustain an audience but also needing to spread them around from one blog to the next. The audience is then serially connected to each other and to a blog that is serially connected to other blogs. Contrary to the assertions of many, including Sarvas, the Internet may disconnect as much as it superficially connects. The sense of interconnectedness produced is akin to a human chain of hand-holders. While any link in 
the chain may feel a real connection to the individuals on the link's left and right, any perceived connection to a link ten individuals down the chain is illusory. The hand holders connect each other but also spread each other farther out creating more distance between the members of the chain. Graham defines this quality of the Internet as a "paradox" that "by decreasing time-distances between people, it simultaneously annihilates existing perceptions of social space, the situated sense of social coherence - belonging - that arises from social interaction" (2002:164). This increased separation and absence of belonging prevents true association and hinders rather than promotes resistance (Brenkman 1979).

\section{Whether Production Can be Isolated from Consumption}

Some herald the arrival of the Internet as a space to create a free economy. Information, the commodity of the Information Society, can be freely traded as seen through "wiki" formats such as Wikipedia and through the use of open source code. Others challenge this assumption and argue that, on the whole, the Internet is simply a further extension of capitalism as it opens up more activities for commodification (Garnham 2001; May 2002). This is, in part, what $n+1$ criticize the litbloggers of, easily succumbing to the capitalist tendencies of publicity and consumption. Still, many litbloggers would probably take issue with that claim. Many appear to have no direct affiliations with corporate interests and choose books for review on the basis of their own interests, often propelled by the urge to bring lesser known works into the public arena. However, while rushing to be producers of knowledge independent and critical of the mainstream, the litbloggers may overlook how they continue to act as unconscious consumers of capitalist credos.

For example, blogrolls often, if not always, appear on the litblogs' sites. [10] These are rosters of other litblogs that the host either reads, approves of, wants others to know exist, or wants others to know that the host knows them to exist. The term "blogrolling" has now been coined. Its definition being the "self-congratulation and mutual admiration" that occurs frequently between the blogs, as they link to each other and cite each other within posts, making the acceptance of the information presented something like a popularity contest, the source being valued rather than the content (Howard 2003). Traffic algorithms used by search engines exacerbate these effects, putting "popular" litblogs at the top of search results. Again, how is this different from what happens in print culture where writers with a certain cache are listened to more readily than others? Similarly, in academic writing, footnote fetishism has created a standard of valuing the merit of a work based on professional visibility (Luke 1999). If an academic's work is cited by others, preferably by other oft-cited academics in big name journals, as measured by citation indexes, then the work is deemed valuable regardless of its content. An academic's desire for professional success is distorted from the goal of academic contribution to the lust of becoming a known "name" (Luke 1999). Likewise, many litbloggers have distorted their goal of promoting unknown literature, instead promoting their unknown selves, hoping to create a "name." Their practices of linking and bloggrolling highlight how neatly litblogs fit within our current literary political economy, substituting exchange value for use value (Agger 1990).

Further, the aura of independence that the litbloggers seek to cultivate, although likely sincere, can help to mask the increased commodification of writing. A customer walking into a big box bookstore may more easily discern that the books stacked in neat piles on the front tables do not necessarily sit there in such prominence due to any internal worth but rather because their publishers paid extra to position them there. However, on the litblogger's site, the presence of the market may be better hidden. An employee of an independent publisher described the marketing of a book through the Internet as "whispering in someone's ear" (Anderson 2005). And a novelist similarly explained that due to the resistance towards the market by the litbloggers, you have to be more subtle when promoting a book on-line (Anderson 2005). This rearguard action is more difficult to notice and correspondingly, to oppose. Like independent movies and alternative music, the supposed independent book culture may also just be part of consumer capitalism.

\section{| What the War Reflects About the Broader Economy of Writing}

With the emergence of the Internet and the World Wide Web, the ability to create words in a digital format that could be shared and circulated faster and more easily than the printed page became a reality. That reality has now 
been labeled a "virtual reality," seemingly separating it from its origins in the "real" reality. While certain streams of discourse have moved on-line, others have remained firmly bound to the fiber page. Some words produced in "real" reality also appear in virtual reality, mirror images that occupy two worlds. Other words are confined to one world or other, occasionally interacting in conversation between digital and printed page. Notions of spatiality and territory generated in the "real" world transfer their meanings to the digital world giving the impression that the digital world can be thought of and constructed as something other than what exists off-line. This gives the authors of discourse written in the printed world the advantage of a perspective that allows them to evaluate how discourse operates in the electronic system of bits known as the Internet.

The pen and paper discussants hold up the web to their printed words like some sort of mirror and evaluate whether discourse on-line accurately reflects the critical reflections they pour onto fibrous page with ink that has spilled from a plastic cartridge housed inside a plastic printer electronically connected to a computer. When the reflected image appears distorted, the real world's discourse sounds rebuke, dismay and even outrage. Why has electronic discourse produced a false likeness, they may ask. In so doing, they create a contrast or a binary between printed text and digital text and further, establish two seemingly fixed realms. This distinction, perhaps without a difference, distracts attention from the fact that no real change has occurred. However, a recognition that these spaces, like all others, "have a meaning that is mediated by an imaginative geography," may invite contestation and change (Shapiro 1991:10).

Concurrently, some, especially those that read the Internet as a digital public sphere that broadens democracy, may want to see litblogs as a subaltern counterpublic. Fraser defines subaltern counterpublics as "parallel discursive arenas where members of subordinated social groups invent and circulate counterdiscourses to formulate oppositional interpretations of their identities, interests, and needs" (Fraser 1992). Litblogs, defined such as subaltern counterpublic, would then seek to expand the confined discourse of the established print media to engage with the oft excluded literary works that fail to fit publishing norms that predetermine what readers want to read. However, this subaltern counterpublic appears to be more of a distorted mirror image of print media's book culture, reproducing much of its structure and rules while merely expanding the amount of text to be digested. Perhaps, the litblogs are just an elegant variation of the establishment print culture?

Warner challenges the "counter" in Fraser's "counterpublics," likening their activity to "the classically Habermasian description of rational-critical publics with the word oppositional inserted" (2002:85). Warner also questions whether Fraser's definition of counterpublics would be limited to the subaltern but would instead also embrace "U.S. Christian fundamentalism, or youth culture, or artistic bohemianism" (2002:86). Warner provides the following revised definition -

\begin{abstract}
A counterpublic maintains at some level, conscious or not, an awareness of its subordinate status. The cultural horizon against which it marks itself off is not just a general or wide public, but a dominant one. And the conflict extends not just to ideas or policy questions, but to the speech genres and modes of address that constitute the public and to the hierarchy among media. The discourse that constitutes it is not merely a different or alternative idiom, but one that in other contexts would be regarded with hostility or with a sense of indecorousness (2002: 86).
\end{abstract}

The increasing conflation of print and digital book culture highlights the misnomer of counterpublic to the litbloggers. The litblogs may be expanding book culture by creating an alternative identity of what book culture can be that meets their interests and needs. However, despite this paper's title, any hostility towards them seems only superficial, and any potential change represented by them appears the same. As Warner states, "[c]ounterpublics are spaces of circulation in which it is hoped that the poesis of scene making will be transformative, not replicative merely" (2002:88). Whether it is fair of $n+1$ and others to put this burden of effecting change on the litblogs is a valid question. More appropriately, perhaps, this analysis demonstrates the shortcomings of arguments that cast the Internet as inherently transformative.

Again, whether the establishment media casts aspersions at the dumbing down of literary criticism on the Internet or whether the Internet enthusiasts adorn the litbloggers with honorary medals for jobs well done, the dominant literary political economy that has substituted exchange value for use value has changed little. Still, to borrow from Fraser, this reports the state of the "actually existing" literary criticism on-line (1992). As Garth Risk Hallberg, one of the blogger contributors to The Millions litblog, commented, perhaps hope remains for a more fruitful discourse.

I'd like to advance the proposition that we're all engaged in a test-case. To the extent that we can do something productive 
with these questions (which will likely involve listening as well as talking, reading as well as writing), we support the idea that the blog has some place at the table of cultural criticism. To the extent that we spend time finding ever more inventive ways to give one another the finger, we prove out the idea that, behind the hypnotic flickering on our shiny new screens, nothing of much worth is happening (Hallberg 2007b).

The challenge really is to create an elevated, more critical discourse in both media forms and not reduce the analysis of the discourse to easy binaries like technology is evil/tradition is good or speed kills/slowness saves.

Moreover, we should not faddishly embrace the Internet as the next possibility to revitalize an increasingly fragmented Left, when its very nature seems to promote a dispersion of thought into a scattered host of ever smaller communities. Our efforts need to be aimed at investigating the ways in which the Internet can truly connect us, if possible, and then focus our energies there. At the same time, we cannot ignore the print world and relegate it to history. The mediums of our message do matter, but they matter less if our message is not being received. And they matter less still if we no longer know what message we are trying to transmit.

\section{Endnotes}

1. "What the blogs have really done is encourage inclusion, encourage people from all walks of life to join the conversation...," as Mark Sarvas, the founder of The Elegant Variation, describes blog democracy (Dotinga 2005).

2. The speed of the Internet cautions me against making any pronouncements of a temporal nature. The majority of the "action" explained below occurred in early 2007. Many on-line and print outlets picked up the story around that time; however, its echoes continue to be heard from time to time in various forms. Still, by the time this text reaches its audience, a more recent dispute may have evolved, The Elegant Variation may no longer exist, and/or $n+1$ may have published its last issue.

3. By more established, I refer to The Elegant Variation's, I refer to its length of existence, its audience size, and its creator's output. He has, of this date, published several reviews with major print outlets and has a novel (Harry, Revised) forthcoming from a major publisherthe U.S. subsidiary of Harry Potter's, in fact. However, established may not equate with "establishment" yet. The site does seek to create a more democratic space for book culture.

4. In fact, The Chronicle of Higher Education also labeled the "sometimes cranky discussion about the purpose of blogs and the amateurization of literary criticism" a war ("Critical Mass: The Lit-Blog Wars" 2007), as did the Los Angeles Times, "Battle of the Book Reviews: A war of words breaks out between print and Internet writers as newspapers cut back coverage" (Getlin 2007).

5. Or perhaps the proliferating and acidic (eroding) effects of blogs could be likened to the fallout from the information bomb (Armitage and Roberts 2002).

6. In a parenthetical, Sarvas explained the motivation for the more than 6,000 word post, "This post is enormous - apologies in advance - but the $n+1$ editors have extolled the virtues of length, urging bloggers to compose 5,000 word pieces, so now they've got one. I hope you'll stick through to the end, holding final judgment in abeyance until then. I've tried to avoid anything that smacks of mere defensiveness though I suspect I haven't been entirely successful" (Sarvas 2007b).

7. The Campaign's efforts to save the AJC's book editor, Teresa Weaver, were not successful. She now works as a part-time books editor at Atlanta magazine and an editor/writer for Habitat for Humanity. A post on the NBCC's blog compared the since reduced book section to a racing form (Brown 2007). Additionally, since the start of the campaign, the Chicago Sun-Times' book section has been cut in half.

8. It is only a guess, but due to the piece's unavailability, some of the comments in response may have been made without the authors having read it, surely not a good way to engage in a productive discourse.

9. For an interesting treatment of Foucault's work as a perpetrator of the increasing fragmentation of leftist political thought, see Sanbonmatsu's The Postmodern Prince (2004).

10. For example, The Elegant Variation's blogroll labeled "Barking at the Moon" contains links to some seventy-eight blogs. 


\section{References}

Agger, Ben. 1990. The Decline of Discourse: Reading, Writing and Resistance in Postmodern Capitalism. New York: The Falmer Press.

-. 1991. "Critical Theory, Poststructuralism, Postmodernism: Their Sociological Revelance.” Annual Review of Sociology 17:105-131.

-. 2004. Speeding Up Fast Capitalism: Cultures, Jobs, Families, Schools, Bodies. Boulder, Co: Paradigm Publishers.

Altheide, David L. 1987. "Format and Symbols in TV Coverage of Terrorism in the United States and Great Britain." International Studies Quarterly 31:161-176.

Anderson, Hephzibah. 2005. "Publishers Must Learn to Whisper on the Web." The Observer, July 3.

Armitage, John and Joanne Roberts. 2002. "Living with Cyberspace: An Introduction to Technology \& Society in the 21 st Century." Pp. 1-13 in Living with Cyberspace: Technology and Society in the 21 st Century, edited by J. Armitage and J. Roberts. New York: Continuum.

“The Blog Reflex: Blog with Me a Spoon." 2007. n+1 5:5-7.

Brenkman, John. 1979. "Mass Media: From Collective Experience to the Culture of Privatization." Social Text Winter:94-109.

Brown, Rodger L. 2007. "Critical Mass: Guest Post: AJC Books, Two Months Later.” Accessed April 1, 2008 (http://bookcriticscircle.blogspot.com/2007/09/guest-post-ajc-books-twomonths-later.html).

Cooke, Rachel. 2006. "Deliver Us From These Latter-Day Pooters.” The Observer, November 26.

CR. 2007. "Long Sunday, 'The Intemperate, the Unconsidered, the Undigested." Accessed March 17, 2007 (http://www.long-sunday.net/long_sunday/2007/02/the_intemperate.html).

Crampton, Jeremy W. 2003. The Political Mapping of Cyberspace. Chicago: The University of Chicago Press.

"Critical Mass: The Lit-Blog Wars." 2007. The Chronicle of Higher Education, April 6, B4.

Dotinga, Randy. 2005. “Book Blogs' Buzz Grows Louder.” The Christian Science Monitor, September 7.

Foucault, Michel. 1997. Ethics: Subjectivity and Truth, Edited by P. Rabinow. Translated by R. Hurley. New York: The New Press.

Fraser, Nancy. 1992. "Rethinking the Public Sphere: A Contribution to the Critique of Actually Existing Democracy." Pp. 109-142 in Habermas and the Public Sphere, edited by C. Calhoun. Cambridge, MA: The MIT Press.

Freeman, John. 2007. "National Book Critics Circle’s Campaign to Save Book Reviews." Accessed April 29, 2007 (http://www. bookcritics.org/?go=saveBookReviews).
Garnham, Nicholas. 2001. "Information Society Theory as Ideology: A Critique." Studies in Communication Studies:129-166.

Getlin, Josh. 2007. "Battle of the Book Reviews: A War of Words Breaks out Between Print and Internet Writers as Newspapers Cut Back Coverage." The Los Angeles Times, May 13.

Graham, Phil. 2002. "Space and Cyberspace: On the Enclosure of Consciousness." Pp. 156-164 in Living with Cyberspace: Technology and Society in the 21 st Century, edited by J. Armitage and J. Roberts. New York: Continuum.

Hallberg, Garth Risk. 2007a. "The Millions (A Blog About Books), 'Keepers of the Flame: A Reply to +1 ." Accessed March 16, 2007 (http://www.themillionsblog.com/2007/03/ keepers-of-flame-reply-to-n1.html).

—. 2007b. "The Millions (A Blog about Books), 'Love: a Burning Thing." Accessed March 18, 2007 (http://www.themillionsblog.com/2007/03/love-burning-thing.html).

Horkheimer, Max and Theodor W. Adorno. 2002. Dialectic of Enlightenment: Philosophical Fragments, Edited by G. S. Noerr. Translated by E. Jephcott. Stanford, CA: Stanford University Press.

Howard, Jennifer. 2003. "It's a Little Too Cozy in the Blogosphere.” The Washington Post, November 16, B1.

Keener, Jessica Brilliant. 2005. "Getting the Word Out: As Those Who Read and Write Books Link Up Online, Blogs Become Places of True Literary Discovery." Boston Globe, May 2.

“The Litblog Co-op." 2007.Accessed March 16, 2007 (http://lbc. typepad.com/).

Luke, Timothy W. 1999. "The Discipline as Disciplinary Normalization: Networks of Research.” New Political Science 21:345-363.

Marx, Karl. n.d. Capital, vol. 1. Moscow: Foreign Languages.

May, Christopher. 2002. The Information Society: A Sceptical View. Cambridge: Polity Press.

McLemee, Scott. 2005. "Read This!" Inside Higher Ed. Accessed April 15, 2007 (http://insidehighered.com/ views/2005/04/11/mclemee4_11).

Press, Joy. 2005. "Book Smart: Could Cyberspace Be the Novel's Best Friend? Litblogs take off--and grow up." The Village Voice, April 19.

Redhead, Steve. 2006. "The Art of the Accident: Paul Virilio and Accelerated Modernity." Fast Capitalism. Accessed January 4, 2008 (http://www.fastcapitalism.com/).

Rich, Motoko. 2007. “Are Book Reviewers Out of Print?” New York Times, May 2. 
Sanbonmatsu, John. 2004. The Postmodern Prince: Critical Theory, Left Strategy, and the Making of a New Political Subject. New York: Monthly Review Press.

Sarvas, Mark. 2007a. “The Elegant Variation.” Accessed March 16, 2007 (http://marksarvas.blogs.com/elegvar/).

-. 2007b. "The Elegant Variation, ' $n+1$ and the Scowcroft Doctrine or The Last Word"' Accessed March 19, 2007 (http:// marksarvas.blogs.com/elegvar/2007/03/n1_and_the_scow. html).

-. 2007c. "The Elegant Variation, 'The $n+1$ Letters \#2'." Accessed March 15, 2007 (http://marksarvas.blogs.com/ elegvar/2007/03/the_n1_letters_1.html).

-. 2007d. "The Elegant Variation, 'The $\mathrm{n}+1$ letters: \#1*'." Accessed March 14, 2007 (http://marksarvas.blogs.com/ elegvar/2007/03/the_n1_letters_.html).

-. 2007e. "The Elegant Variation, 'The $n+1$ letters: \# 1A'." Accessed March 12, 2007 (http://marksarvas.blogs.com/ elegvar/2007/03/the_n1_letters_2.html).

-. 2007f. "The Elegant Variation, 'Tuesday Marginalia."Accessed March 13, 2007 (http://marksarvas.blogs.com/ elegvar/2007/03/tuesday_margina.html).

-. 2007g. "Mark Sarvas on 'The Hot Zone'." Truthdig Weekly Book Reviews. Accessed November 8, 2007 (http://www.truthdig.com/arts_culture/ item/20071108_mark_sarvas_on_the_hot_zone/).
Scott, A. O. 2005. "Among the Believers." New York Times, March 17, 2007.

Sebeok, Thomas A. 1985. "Enter Textuality: Echoes from the Extra-Terrestrial.” Poetics Today 6:657-663.

Shapiro, Gary. 2004. “'New' New York Intellectuals." The New York Sun, July 26, 14.

Shapiro, Michael J. 1989. “Textualizing Global Politics.” Pp. 11-22 in International/Intertextual Relations: Postmodern Readings of World Politics, edited by J. Der Derian and M. J. Shapiro. Lexington, MA: Lexington Books.

-. 1991. Reading the Postmodern Polity: Political Theory as Textual Practice. Minneapolis, MN: University of Minnesota Press.

Trachtenberg, Jeffrey A. 2007. "Scarcity of Ads Endangers Newspapers' Book Sections.” The Wall Street Journal, March 6, B1.

Tucker, Genevieve. 2006. "Online, Everyone's a Critic." The Australian, December 6.

Warner, Michael. 2002. "Publics and Counterpublics." Public Culture 14:49-90.

Wasserman, Steve. 2007. "Goodbye to All That: The Decline of the Coverage of Books isn't New, Benign or Necessary." Columbia Journalism Review 46:42-53. 
